\title{
Corrigendum
}

\section{Survival and cause of death after traumatic spinal cord injury. A long-term epidemiological survey from Denmark}

A Hartkopp, H Brønnum-Hansen, A-M Seidenschnur, F Biering-Sørenson

Spinal Cord 1997; 35: 76-85.

Since publication of the above paper the authors have noted certain errors in their calculations details of which follow.
In connection with supplementary analyses of our database evaluating the risk of suicide among spinal cord injured, we found an error in the computation of person years for the first $(1953-1973)$ observation period. This miscalculation resulted in a systematically overestimation of the mortality in this early period. As a consequence our remarks in the discussion and our conclusions regarding the mortality changes over time from the first $(1953-1973)$ to the second $(1972-1990)$ observation period shall be taken with some caution, and specially for the men they are not valid. The corrected Tables 4 and 7, and Figure 2 are now provided.

Table 4 Standardised mortality ratios (SMRs) for various causes of death by gender. Period of injury 1953-1971. End of follow-up: December 31, 1973. An empty cell indicates that only 0 or 1 death recorded, and this is why SMR is not given

\begin{tabular}{llcl}
\hline Cause of death & Men & SMR $(95 \%$ Confidence limit $)$ & All \\
\hline Neoplasms & - & - & - \\
Cardiovascular diseases & $1.22(0.53-2.41)$ & - & $1.25(0.57-2.38)$ \\
$\quad$ Ischemic heart disease & - & - & $0.41(0.05-1.49)$ \\
$\quad$ Cerebrovascular disease & - & - & - \\
$\quad$ Lung embolus & $45.0(9.27-131)$ & - & $38.5(7.93-112)$ \\
Other natural causes & $11.3(7.65-16.2)$ & $21.3(8.55-108)$ & $12.4(8.76-17.1)$ \\
$\quad$ Septicaemia & $234(28.3-845)$ & - & $317(65.4-927)$ \\
Lung diseases & $17.3(9.47-29.1)$ & $30.0(3.63-43.8)$ & $18.3(10.4-29.7)$ \\
Pneumonia & $35.2(14.2-72.5)$ & $71.9(8.70-260)$ & $39.7(18.2-75.4)$ \\
$\quad$ Lung diseases excl. pneumonia & $11.5(4.62-23.7)$ & - & $10.8(4.34-22.2)$ \\
Digestive organs & $5.81(1.20-17.0)$ & - & $5.19(1.07-15.2)$ \\
$\quad$ Urogenital system & $10.3(2.12-30.0)$ & - & $8.65(1.78-25.3)$ \\
$\quad$ Uncertain & $29.1(11.7-59.9)$ & $120(24.7-350)$ & $37.6(18.0-69.2)$ \\
Uraemia & $669(246-1456)$ & - & $674(271-1389)$ \\
$\quad$ Uncertain excl. uraemia & - & $84.7(10.3-306)$ & $11.7(2.42-34.3)$ \\
$\quad$ Urogenital system and uraemia & $29.8(13.6-56.7)$ & - & $28.0(13.4-51.5)$ \\
Accidents and suicide & $1.51(0.31-4.42)$ & $14.1(1.71-51.1)$ & $2.35(0.76-5.49)$ \\
$\quad$ Accidents & - & - & $1.55(0.19-5.60)$ \\
$\quad$ Suicide & $2.60(0.32-9.40)$ & - & $3.59(0.74-10.5)$ \\
Total & $2.80(2.02-3.78)$ & $6.08(2.91-11.2)$ & $3.12(2.33-4.10)$ \\
\hline
\end{tabular}




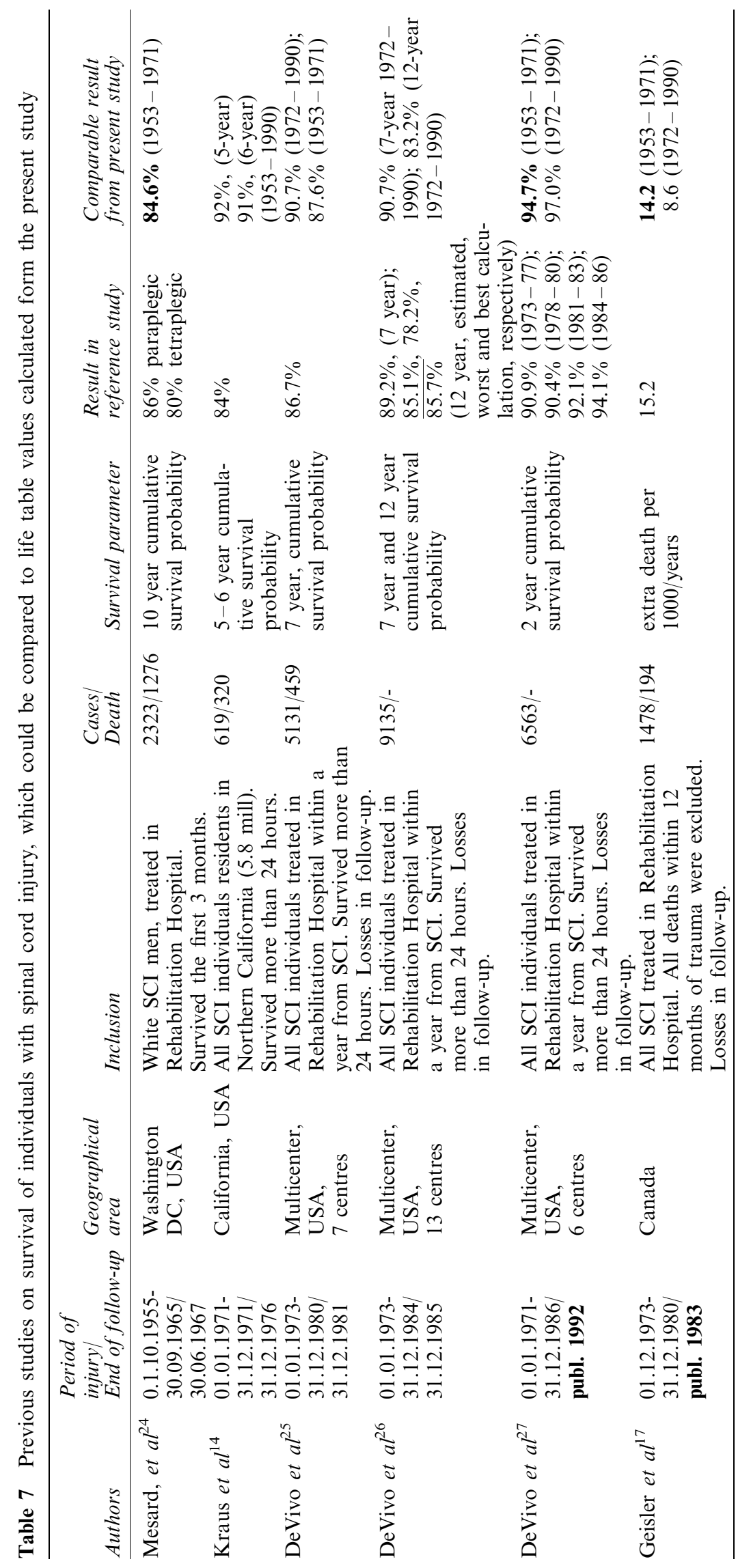



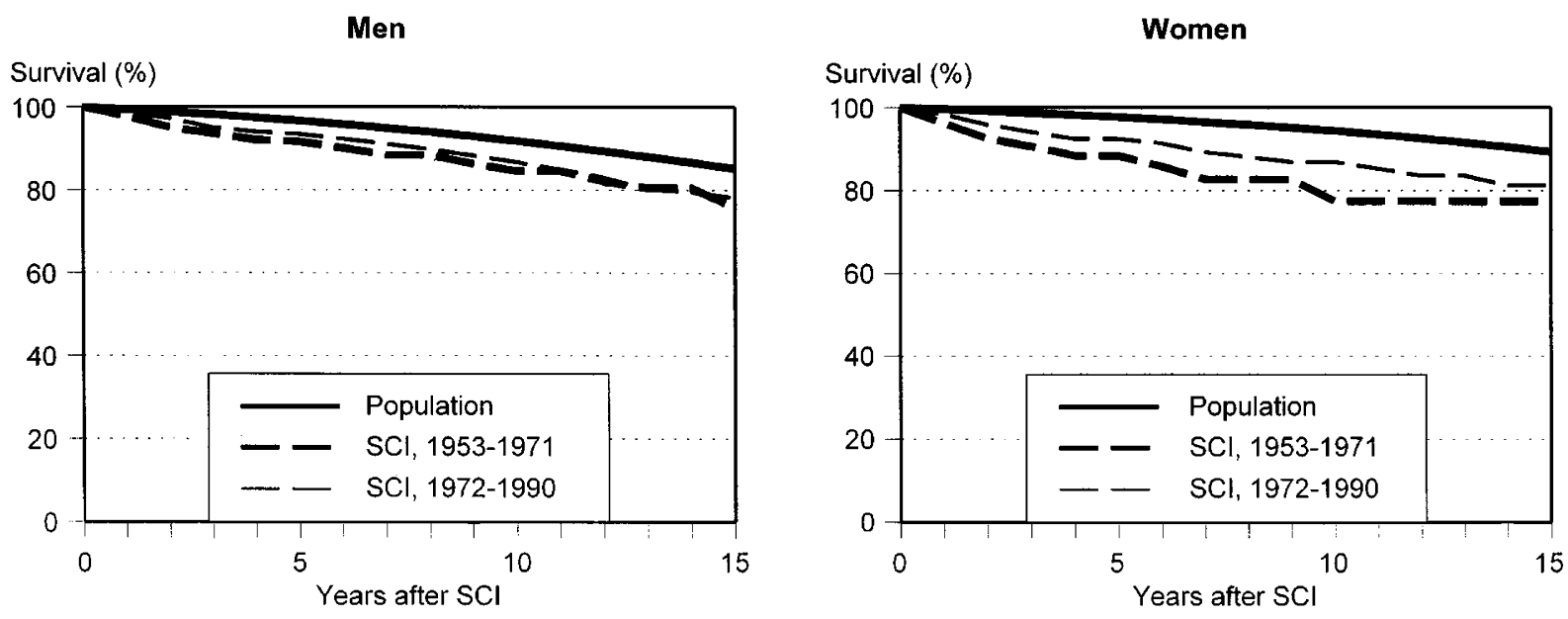

No visible difference between survival for the matched populations 1953-1971 vs 1972-1990.

Figure 2 Survival probability of spinal cord injured individuals and of matched general population. Periods of injury: 19531971. End of follow-up: December 31, 1973. 1972-1990. End of follow-up: December 31, 1992 